\title{
Molecular characterization of Candida spp. isolates from patients with bloodstream infections
}

\author{
Paula Cristhina Niz Xavier ${ }^{[1]}$, Marilene Rodrigues Chang ${ }^{[2]}$, \\ Claudete Rodrigues Paula ${ }^{[3]}$, Flávia Emi Matsumoto ${ }^{[3]}$, Marise Dutra Asensi ${ }^{[4]}$, \\ Maria de Fátima Cepa Matos ${ }^{[2]}$ and Renato Andreotti ${ }^{[5]}$
}

[1]. Programa de Pós-Graduação, Universidade Federal do Mato Grosso do Sul, Campo Grande, MS. [2]. Departamento de Farmácia e Bioquímica, Universidade Federal de Mato Grosso do Sul, Campo Grande, MS. [3]. Departamento de Microbiologia, Instituto de Ciências Biológicas, Universidade de São Paulo, São Paulo, SP. [4]. Departamento de Enterobactérias, Instituto Oswaldo Cruz, Fundação Oswaldo Cruz, Rio de Janeiro, RJ. [5]. Empresa Brasileira de Pesquisa Agropecuária, Gado de Corte, Campo Grande, MS.

\section{ABSTRACT}

Introduction: The aim of this study was to conduct an epidemiological study comparing the genetic similarity of yeasts isolated from blood cultures. Methods: Random amplification of polymorphic DNA (RAPD) techniques were used for the Candida samples obtained from patients at the Hospital Universitário da Universidade Federal do Mato Grosso do Sul (HU/UFMS) in Campo Grande, State of Mato Grosso do Sul, Brazil, from 1998-2000. Results: The most frequently isolated species was Candida albicans (45.8\%). DNA amplification from genomic yeast isolates indicated a genetic similarity of over $90 \%$. Conclusions: The RAPD profiles obtained were able to differentiate between the isolated Candida species, thereby suggesting that the method might be useful in epidemiological studies.

Keywords: Candida. Polymerase chain reaction. Random amplification of polymorphic DNA.

Invasive candidiasis is the fourth leading cause of bloodstream infection in cases of nosocomial infection by fungi. Candida albicans is the most often isolated species, accounting for approximately $50 \%$ of cases $^{1}$. Molecular techniques have been performed to aid epidemiological studies ${ }^{2,3}$.

This retrospective study was conducted using clinical samples obtained from the mycology collection of the laboratory of the Hospital Universitário da Universidade Federal do Mato Grosso do Sul (HU/UFMS) in Campo Grande, State of Mato Grosso do Sul, Brazil. The yeasts were previously detected in blood cultures using an automated system, BACTTEC ${ }^{\mathrm{TM}} \mathrm{FX}(\mathrm{BD}$, New Jersey, USA) as a routine hospital practice, and the three most frequently isolated species were selected for genotypic analysis.

The study was approved by the University Federal do Mato Grosso do Sul Ethics Committee. The molecular tests were conducted in the Laboratory of Animal Health at the Brazilian Enterprise for Agricultural Research (EMBRAPA) according to the protocol described by Valério et al. ${ }^{3}$. The dendrogram was created using GelCompar II (Applied Maths, Kortrijk, Belgium) in the Enterobacteria Laboratory of Fundação Oswaldo Cruz, RJ. Similarity was evaluated using

\footnotetext{
Address to: Dra Paula Cristina Niz Xavier. Rua Itacaja 06/Casa 49, Res. Guarani, 79092-400 Campo Grande, MS, Brasil.

Phone: 5567 9283-6620.

e-mail: paulaxavier80@yahoo.com.br

Received 16 October 2010

Accepted 25 July 2012
}

Pearson's coefficient. For purposes of epidemiological analysis, the strains that showed $>90 \%$ similarity or had a dendrogram showing a single insertion or inclusion were considered similar or belonging to the same clone ${ }^{4}$.

The species implicated in the infectious episodes were Candida albicans, 44 (45.8\%), Candida parapsilosis complex 33,(34.4\%), Candida tropicalis, 14 (14.6\%) and Candida glabrata, $5(5.2 \%)$.

The electrophoretic profiles of the Candida albicans and Candida parapsilosis complex strains demonstrated a predominance of profile A (Figures 1 and 2).

The frequency of systemic infections caused by Candida has increased considerably, particularly in patients hospitalized in critical areas because of the use of immunosuppressive agents, invasive medical procedures, and underlying diseases that may contribute to yeast proliferation ${ }^{2,5}$. Among infecting yeasts, C. albicans is the most common in cases of hospital-acquired infections in several countries ${ }^{1}$.

The present results demonstrate that the method was limited to detecting intra-specific polymorphisms within clones of the same species using only one primer pair ${ }^{2,3}$. The profiles obtained using random amplification of polymorphic DNA (RAPD) were able to differentiate between the Candida species, but few differences between strains of the same species were observed. Nevertheless, the dendrograms showed a genetic similarity $>90 \%$, suggesting that the method might be useful for epidemiological studies and detection during hospital outbreaks. 


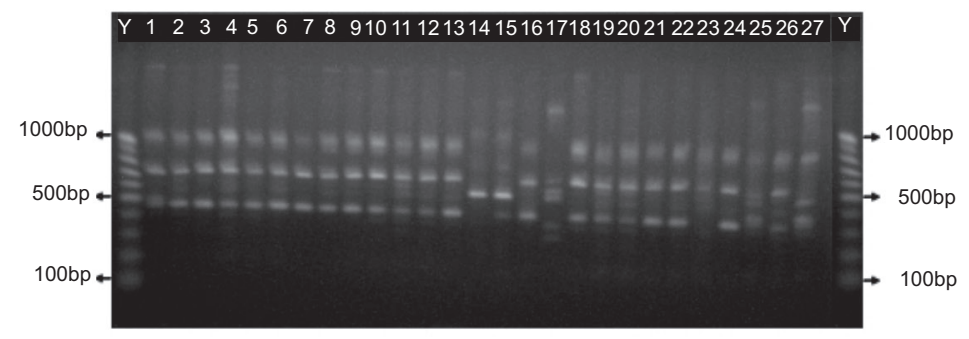

(A)

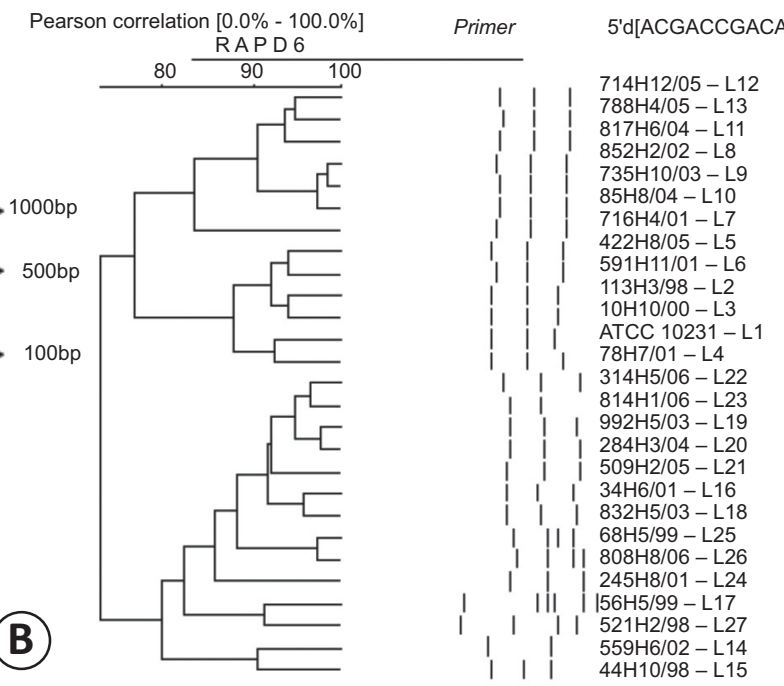

FIGURE 1 - (A) An example of the random amplification of polymorphic DNA patterns obtained with primer OPG-17 5'd [ACGACCGACA] - 3' using Candida albicans isolates. Line Y: 100-pb ladder (Invitrogen); Line 1: Positive control (ATCC) 10231; and L2-L27, samples isolated from bloodstream infections. (B) Dendrograms showing the genotypic profiles of the Candida albicans isolates. Clinical samples were obtained from patients at the University Hospital in Campo Grande, State of Mato Grosso do Sul, Brazil.

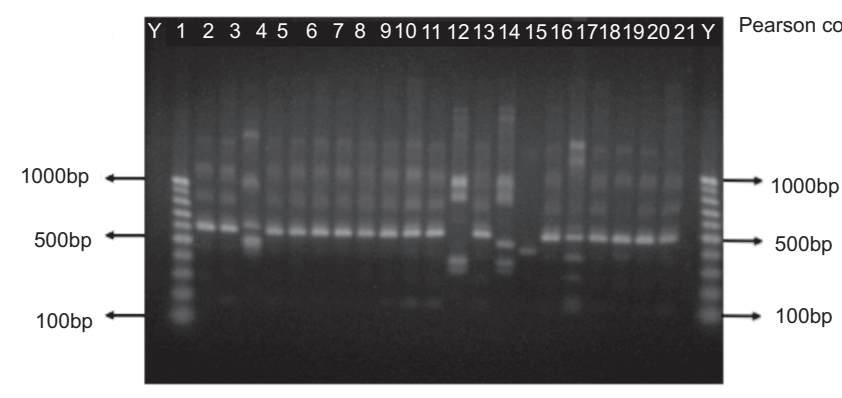

(A)
(B)

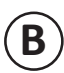

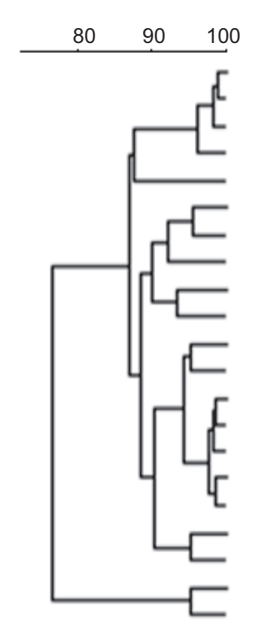
$\underline{\text { RAPD } 3}$ Primer 5 'd[ACGACCGACA]-3

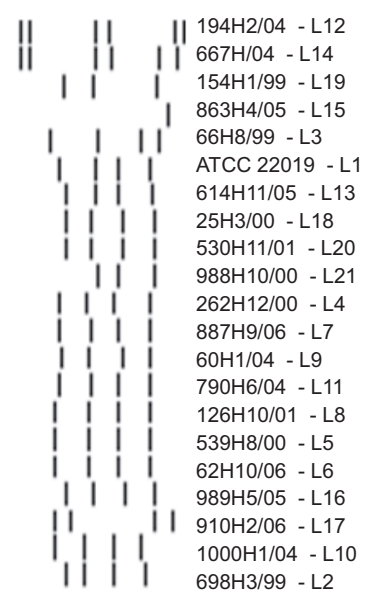

FIGURE 2 - (A) Agarose gel electrophoresis (1.8\%) following random amplification of polymorphic DNA-polymerase chain reaction (RAPD-PCR) using the primer 5'd [ACGACCGACA] - 3 'indicated different genetic patterns for the Candida parapsilosis isolates that had caused bloodstream infections. Line Y: 100-pb ladder (Invitrogen); Line 1: ATCC 22019; Line 2-21: the samples isolated from bloodstream infections (B) Dendrograms showing the genotypic profile of Candida parapsilosis isolates. Clinical samples were obtained from patients at the University Hospital in Campo Grande, State of Mato Grosso do Sul, Brazil.

\section{ACKNOWLEDGMENTS}

The authors thank Fundect-MS, Embrapa Beef Cattle, and the UFMS Dean for Research for their financial support.

\section{CONFLICT OF INTEREST}

The authors declare that there is no conflict of interest.

\section{REFERENCES}

1. Maluche ME, Santos JI. Candida sp. e infecções hospitalares: aspectos epidemiológicos e laboratoriais. RBAC 2008; 40:65-67.
2. Pinto PM, Resende M, Koga-Ito CY, Tendler M. Genetic variability analysis among clinical Candida spp. Isolates using randon amplified polymorphic DNA. Mem Inst Oswaldo Cruz 2004; 99:147-152.

3. Valério HM, Weikert-Oliveira RCB, Resende MA. Differentiation of Candida species obtained from nosocomial candidemia using RAPD-PCR technique. Rev Soc Bras Med Trop 2006; 39:174-178.

4. Resende PCJ, Franco GR, Rosa CA, Hahn RC, Hamdan JS. Phenotypic and genotypic identification of Candida spp. isolated from hospitalized patients. Rev Iberoam Micol 2004; 21:24-28.

5. Hinrichsen SL, Falcão E, Vilella TAS, Colombo AL, Nucci M, Moura L, et al. Candidemia em hospital terciário do nordeste do Brasil. Rev Soc Bras Med Trop 2008; 41:394-398. 